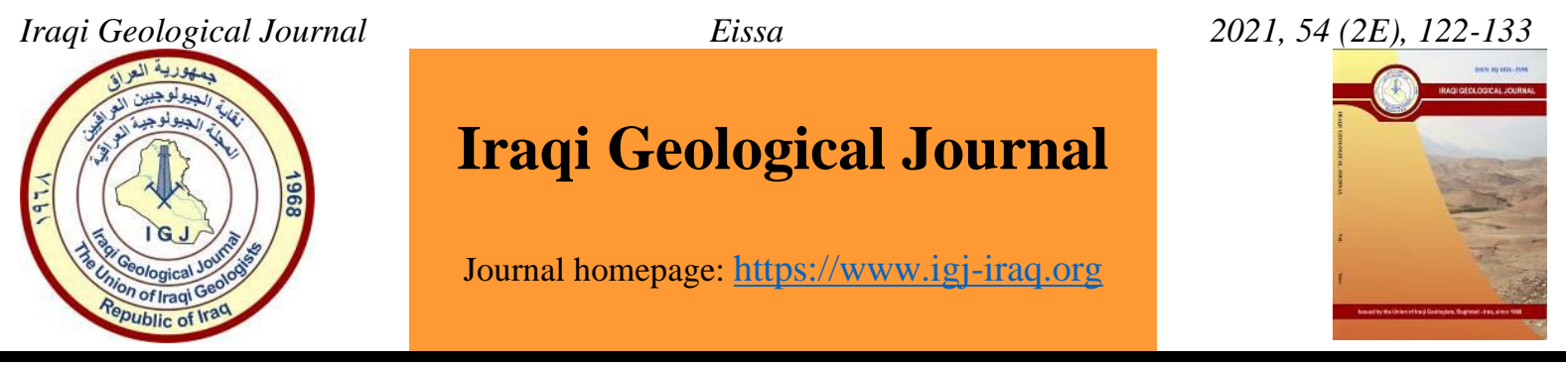

\title{
Electrical Resistivity Tomography Application for Buried Foundation Investigations: Insights and Review
}

\author{
Raad Eissa ${ }^{1,2, *}$ \\ 1 School of Geography, Geology and Environment, William Smith Building, Keele University, UK \\ 2 Department of Civil Engineering, College of Engineering, University of Kerbala, Kerbala, Iraq \\ * Correspondence: raad.m@uokerbala.edu.iq
}

Received: 7 June 2021; Accepted:9 August 2021; Published: 30 November 2021

\begin{abstract}
Maintenance of existing structures and development or reuse of brownfield sites need to determine buried foundations, in terms of location and dimensions, as accurately as possible. Geophysical methods provide an indirect way to look in the ground and provide information about the subsurface that the traditional methods might be unable to. In particular, the electrical resistivity method has been performed in the context of buried foundation surveys. This review spots the light on the main results obtained from utilizing the electrical resistivity method and the most affecting parameters that can influence the obtained resistivity models, and also, focuses on published case studies to merge their findings to understand the interaction among the method, the foundation and the hosting background for buried foundations surveys. The case studies mentioned in this review show the resistivity method success and highlight the most important parameters that can control the method's applicability and data interpretation. The integration of the geophysical-traditional methods has appreciable potential for more accurate findings.
\end{abstract}

Keywords: Buried foundation; Electrical resistivity; Array; Site investigation

\section{Introduction}

Buried foundations can be defined as the foundation of an existing building or the left behind foundations of any pre-existing buildings after demolishing. The main objective of any building foundations is to anchor the building to the ground and it is used for different kinds of buildings and/or infrastructures (for example, commercial buildings, bridges, dams and houses), (Reynolds, 2011). The type of foundation can be decided based on the ground and the structure. To satisfy the needs of any project, shallow foundations (e.g. spread footings, strip footings, combined footings) or deep foundations (e.g. driven piles, piers, caissons) might be used. These days, most of the foundations can be built using concrete and reinforced concrete whilst wood, bricks and stone blocks were used in most of the ancient foundations, as we can see on archaeological foundations, for example, Giocoli et al. (2019) determine masonry walls as buried foundations of the Orvieto Cathedral, Umbria, central Italy. Regardless of the type and the construction material of buried foundations, it generates a subsurface anomaly embedded in the hosting ground. Consequently, buried foundations can produce local change in the physical properties of the hosting ground, for example, electrical resistance, therefore, it is

DOI: $10.46717 /$ igj.54.2E.8Ms-2021-11-24 
possible to perform electrical resistivity tomography (ERT) method to image the subsurface and to determine buried foundations.

The electrical resistivity tomography method is one of the known and non-destructive geophysical electrical method. Due to the method's simplicity, rapid pursuance and cost-effective characteristics, it has wide range and has been applied for different purposes, for example, geotechnical and site investigation studies. On the other hand, the electrical resistivity method suffers from some limitations such as ambiguity in the data interpretation. The ambiguity might be the most important limitation of the method where many subsurface anomalies can produce same observed measurements, (Keary et al., 2002).During the last decades, the ERT method has been performed for buried foundations investigations. Although, the observed foundations were built using same construction material (e.g. concrete, rock blocks and so on), different resistive anomalies were imaged. This difference in resistivity readings where related to several parameters, for example, deterioration process of the foundation, groundwater level and dissolved ions concentration, and presence of reinforcing material (i.e. steel bars in the reinforced concrete). Abu-Zeid et al. (2006) eliminate three different resistivity ranges of a brick wall foundation, and as follow: high resistivity volume of the wall $(>150 \Omega \mathrm{m})$ was interpreted due to presence of voids and fractures; an intermediate resistivity volume (20-100 $\Omega \mathrm{m})$ was explained by wellpreserved parts of the wall foundation; and low resistivity volume $(<10 \Omega \mathrm{m})$ was found due to complete deterioration of bricks and full replacement by completely degraded slat mud material.

In this study, a review and certain insights related the electrical resistivity tomography method to buried foundation investigations are highlighted and discussed such as data acquisition and different inversion algorithms effects on the obtained models. Moreover, some of the published case studies, that performed by other researchers, are also presented.

\section{Theoretical Background of the Resistivity Method}

As other geophysical methods, the electrical resistivity depends on a certain physical property of the ground. It relies mainly on the ground's electricity which ultimately depends on material type and the groundwater chemistry in the pores. The physical concept of the method relies on Ohm's law, during the passage of electrical current $(I)$, a potential drop $(V)$ can be happened due to the resistance $(R)$ of the ground material, the resistance can be written in the following way (Reynolds, 2011):

$$
R=V / I
$$

The resistance is governed not only by the ground material type and the fluid's chemistry but also by the shape and dimensions of the electrical current route (i.e. wire). It is proportional to the length $(L)$ of the resistive ground material and inversely proportional to its cross-sectional area $(A)$, this can be written in the following way:

$$
R \propto L / A
$$

With $\rho$ as a proportionality constant, equation 2 can be rewritten as:

$$
R=\rho L / A
$$

From equations 1 and 3 , the resistivity can be calculated by the following equation

$$
\rho=V A / I L(\Omega \mathrm{m})
$$

When we consider a single current source (i.e. single electrode) injecting the current in a uniform resistivity medium, the current will be radially distributed as a hemisphere and the electrode is the centre. At a certain distance $(r)$, from the electrode, the hemisphere's surface area is $2 \pi r^{2}$ and the current density $(i)$ is:

$$
\mathrm{i}=\mathrm{I} / 2 \pi \mathrm{r}^{2}
$$

With increasing in the electrode spacing (a) the current hemisphere increases and therefore, the current intensity decreases. To measure the voltage at any point in the ground, another expression which is 
called the geometric factor $(k)$, should be involved. The potential at $M$ and $N$ can be calculated as following:

$$
\begin{aligned}
& v M=\frac{\rho I}{2 \pi}\left[\frac{1}{A M}-\frac{1}{M B}\right] \\
& v N=\frac{\rho I}{2 \pi}\left[\frac{1}{A N}-\frac{1}{N B}\right]
\end{aligned}
$$

Measuring the potential difference $(v M N)$ can be much easier;

It can be rewritten:

$$
v M N=v M-v N=\frac{\rho I}{2 \pi}\left\{\left[\frac{1}{A M}-\frac{1}{M B}\right]-\left[\frac{1}{A N}-\frac{1}{N B}\right]\right\}
$$

$$
\rho=\frac{2 \pi \rho v m n}{I\left\{\left[\frac{1}{A M}-\frac{1}{M B}\right]-\left[\frac{1}{A N}-\frac{1}{N B}\right]\right\}}
$$

For each electrode configuration, there is a geometric factor which can be expressed by:

$$
k=\frac{2 \pi}{\left[\frac{1}{A M}-\frac{1}{M B}\right]-\left[\frac{1}{A N}-\frac{1}{N B}\right]}
$$

From equation $1, R=V / I$, the apparent resistivity can be rewritten as:

$$
\rho=R k
$$

\section{How the ERT Survey Executed}

Through an electrical resistivity survey, variation in the electrical resistance of the ground can be measured and recorded via a pair of electrodes for current injection and another pair of electrodes for potential difference. These electrodes are pushed into the ground and connected to a certain meter for calculating the electrical resistance by a set of wires. The meter is connected to a laptop which is controlled by a specific software package for controlling the survey's setup. The four electrodes can be set up in different arrangements named arrays or electrode configurations. Each electrode configuration has its own merits and limitations over the others. The number of electrodes in a survey and the distance between any two adjacent electrodes, named electrode spacing (a), can govern the imaged cross-section underneath the electrodes horizontally and vertically. The longer configuration, the longer cross-section and the deeper tested point in the ground. On the other hand, the wider electrode spacing generates less data resolution.

One of the main rules of the resistivity meter is to switch, for every single reading, the electrodes to another set of four electrodes to move the survey forward until the second end of the array. After that, the meter starts from the beginning but uses double of the electrode spacing (2a) to investigate deeper or the second level (n2), the third level (n3) using 3 times of the electrode spacing (3a). The controller software package manages this procedure until the last possible level of surveying (last n), (Fig 1). Using this survey manner, variations in the ground resistivity can be imaged; any higher or lower resistivity, comparing with the background's resistivity, then can be recognized as an anomaly. Buried foundations almost generate higher resistivity values than the background environment. From this feature of the electrical resistivity method, it has been distinguished and applied as a useful indirect geophysical method for searching unknown buried foundations.

\section{Material and Methods}

A literature search for the most pertinent publications to the buried foundations studies was undertaken. From those publications the influencing parameters on the electrical resistivity of buried foundations were identified. Based on the details that presented in the published studies, the buried foundations have been investigated by numerical and real-world scenarios (Figs. 3 and 4). 


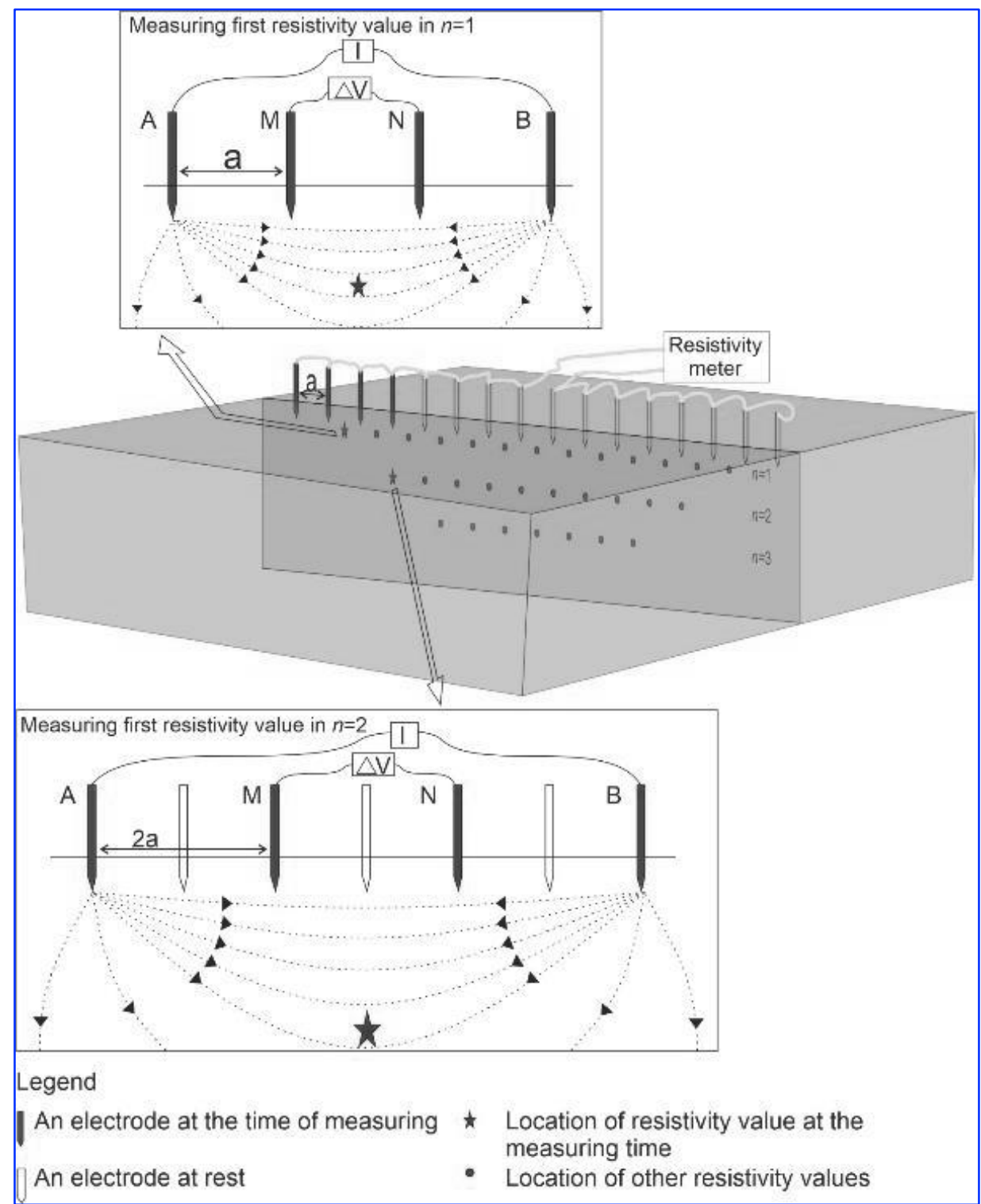

Fig 1. Electrical resistivity survey using a multi-electrode system to generate a $2 \mathrm{D}$ electrical resistivity cross-section

\section{Factors Affecting the ERT Method for Buried Foundations Investigation}

The electrical resistivity method, as other geophysical methods, has advantages (e.g. non-direct method) and limitations (e.g. ambiguity) and it can be influenced by several parameters (e.g. moisture content, lithological composition). One of the ERT's limitations is the ambiguity of the method where the underground can be represented by many different models. Moisture in the ground is one of the important ways for the electrical current to move through the ground and the same site can have different resistivity response if the moisture content changes. Consequently, any resistivity model is the final product of the interaction of the advantages, limitations and affecting parameters.

\subsection{Data Resolution}

The electrode spacing is the main factor that can govern data resolution. The shorter electrode spacing is the higher data resolution. Data resolution and foundation dimensions are quite related to each other. Small foundations need shorter electrode spacing to be imaged. Eissa et al., (2019) were able to 
detect a buried brick wall in perpendicular profiles to the longest dimension of the buried wall, using $0.25 \mathrm{~m}$ electrode spacing, although the target dimension is $0.36 \mathrm{~m}$. Obviously, the electrode spacing should be smaller than the buried foundation dimension to ensure that one or more resistivity points are responded from the foundation otherwise the target might be lost between two adjacent points.

\subsection{Data Quality}

Data quality might be another important factor for buried foundation investigation. The data without many anomalous points (compared with adjacent data points and considering points from the target location) might help not only to detect the buried foundation but also to generate more sensible resistivity models with a sufficient agreement with the actual underground situation. Eissa et al. (2019) found pole-pole and pole-dipole arrays were the worst arrays due to many bad points distributed over the obtained profiles. Although the buried foundation was detected, its shape and resistivity values on the $2 \mathrm{D}$ cross-section were not representative enough to be eliminated from the background. The bad points were obtained due to the remote electrodes and to availability of noise; different electrical sources like cables around the site. In noisy sites, electrode configurations with good signal to noise ratio, for example, Wenner array, are recommended. Several studies have been conducted in difficult situations, for example, urban and electrically noisy sites (i.e. poor signal to noise ratio) and they were able to get a reasonable response of the buried foundation, for example, Chitea et al. (2019) and Kermani et al. (2014).

\subsection{The Array Type}

Different array types have different effects on the efficiency of the ERT method to detect and eliminate buried foundations. Chambers et al. (2002) employed Wenner and dipole-dipole arrays, using full 3D inversion, to image buried walls. They found that the dipole-dipole array was more accurate in revealing the wall geometry compared with the Wenner array; on the Wenner model the wall looks diffused and patchy. Eissa et al., 2019 found the Wenner array is more sensitive to the bottom of the foundation whilst dipole-dipole array is more sensitive to the top of the foundation. That might be related to the sensitivity of the arrays. The Wenner array is comparatively sensitive to resolve vertical changes below the center of the array and poor in resolving horizontal changes. Dipole-dipole array is good to resolve horizontal changes and relatively poor to detect vertical changes in the resistivity, (Loke, 2004). As any buried foundation can have and show the horizontal and the vertical changes in the underground resistivity, therefore, the Wenner and dipole-dipole might be the best two arrays for buried foundations investigations, especially if they conducted to detect the same target and their results compared qualitatively.

On the other hand, the Wenner array has the smallest geometric factor among the other arrays, this can be another merit for the array and makes it a suitable choice in electrically noisy sites but it has smaller horizontal coverage compared with dipole-dipole array. The dipole-dipole array can cover most of the cross-section underneath the array which makes it a suitable electrode configuration to be used with a small number of electrodes and in small sites, (Loke, 2004) (Fig. 2 and Table 1) for the different electrode configurations employed for buried foundation investigations. Fig. 2 shows that dipole-dipole array is the most frequent array that has been utilized in resistivity surveys for buried foundation studies. That might be related to the merits of the array over all other arrays, for example, the better horizontal coverage, the sensitivity to the vertical and horizontal changes and to the signal to noise ratio. 
Table 1. Published case studies performing electrical resistivity method for buried foundations with the studied target, electrode configuration information; Wenner (W), Schlumberger (S), WennerSchlumberger (WS), Gradient plus (G), Dipole-dipole (D), Pole-dipole (PD), Cross-hole resistivity (C), and Pole-pole (P)

\begin{tabular}{|c|c|c|}
\hline Authors & Utilized array(s) & Brief information about the studied foundation \\
\hline Su et al. (2020) & $\mathrm{C}$ & $\begin{array}{l}\text { The cross-hole resistivity succeeded in imaging reinforced concrete } \\
\text { bridge pile foundation within } 20 \mathrm{~m} \text { and electrode spacing } 1 \text { or } 0.5 \mathrm{~m} \text {. }\end{array}$ \\
\hline Gündoğdu et al. (2020) & $\mathrm{D}$ & $\begin{array}{l}\text { Bridge pillar foundations were determined and eliminated from hosting } \\
\text { background; using focusing inversion technique. Underneath the bridge } \\
\text { foundation, clayey weak zones were also recognized. }\end{array}$ \\
\hline Giocoli et al. (2019) & WS & $\begin{array}{l}\text { A masonry walls foundation of the Orvieto Cathedral, central Italy, were } \\
\text { imaged and eliminated from the surrounding material, the resistivity } \\
\text { range of the foundation was } 200-2300 \text {. }\end{array}$ \\
\hline Eissa et al. (2019) & $\mathrm{W}, \mathrm{D}, \mathrm{PD}, \mathrm{P}$ & $\begin{array}{l}\text { Brick wall already built in a well-sorted } 4 \mathrm{~mm} \text { gravel pit. The bricks } \\
\text { were in good condition at the time of the pit construction. }\end{array}$ \\
\hline Chitea et al. (2019) & $\mathrm{W}$ & $\begin{array}{l}\text { An old building foundation consisted of two layers, layer } 1 \text { containing } \\
\text { compacted debris of reinforced wall, and layer } 2 \text { containing reinforced } \\
\text { concrete pillars and concrete blocks. }\end{array}$ \\
\hline Al-Saadi et al. (2018) & $\mathrm{D}$ & $\begin{array}{l}\text { Foundations and walls of a Roman villa were successfully imaged using } \\
\text { 3D inversion. The ERT models coincide with historical excavation. The } \\
\text { imaged foundations were built from a layer of gravel at the bottom, } \\
\text { conglomerates and quartzite rock fragments in the middle, and at the top } \\
\text { rectangular sandstone blocks. }\end{array}$ \\
\hline Cardarelli et al. (2018) & $\mathrm{D}$ & $\begin{array}{l}\text { Bricks and pozzolanic mortar were mainly used as a building material, } \\
\text { faced by masonry surfaces with some degradation signs appearing on it; } \\
\text { exfoliation, delamination, and chipping. }\end{array}$ \\
\hline Evangelista et al. (2017) & WS & $\begin{array}{l}\text { The target (i.e. the buried foundation) is } 8 \mathrm{~m} \text { thick of building rubble and } \\
\text { finer anthropic material. }\end{array}$ \\
\hline Lysdahl et al. (2017) & G & $\begin{array}{l}\text { A concrete foundation block and plate, and underneath it a layer of } \\
\text { filling material containing gravel, stone, bricks, and black shale }\end{array}$ \\
\hline Cardarelli et al. (2016) & $\mathrm{D}$ & $\begin{array}{l}\text { The main building materials were bricks and mortar that have suffered } \\
\text { from some decay processes, for example, cracking, exfoliation, } \\
\text { efflorescence and delamination. }\end{array}$ \\
\hline Vargemezis et al. (2016) & $\mathrm{D}$ & $\begin{array}{l}\text { Buried building foundation containing aggregate, cement blocks, and } \\
\text { might be other different material. }\end{array}$ \\
\hline Arjwech and Everett (2015) & $\mathrm{D}$ & Unknown, narrow, and vertical concrete bridge foundation \\
\hline Wang and $\mathrm{Hu}(2015)$ & --- & Reinforced concrete bridge foundation (footing). \\
\hline Fernández et al. (2015) & WS & Arranged gypsum and limestone slabs in a gravel bed \\
\hline Tucker et al. (2015) & $\mathrm{D}$ & $\begin{array}{l}\text { Site } 1 \text {, reinforced concrete long slender bridge piles }(0.4 \times 0.4 \mathrm{~m}) \text {. Site } 2, \\
\text { circular reinforced concrete bridge pile }(0.75 \mathrm{~m} \text { diameter }) .\end{array}$ \\
\hline Kermani et al. (2014) & $\mathrm{S}, \mathrm{W}, \mathrm{D}$ & $\begin{array}{c}\text { At site 1, circular reinforced concrete bridge piers resting on a group of } \\
\text { cast-in-place concrete piles. At site 2, a rectangular reinforced concrete } \\
\text { bridge resting on a group of steel piles. }\end{array}$ \\
\hline Arjwech et al. (2013) & $\mathrm{D}$ & $\begin{array}{l}\text { Bridge foundations of different types (e.g. footings) and different sizes. } \\
\text { Containing reinforced concrete and concrete. }\end{array}$ \\
\hline Wang, $\mathrm{Hu}$ and Wang (2013) & $\mathrm{D}, \mathrm{PD}$ & Reinforced concrete bridge piles. \\
\hline Wu and Lin (2013) & $\mathrm{W}, \mathrm{D}, \mathrm{WS}, \mathrm{P}$ & $\begin{array}{l}\text { Numerical study to evaluate the ERT method for buried foundation } \\
\text { detection. The ground assumed to have } 100 \Omega \text {.m whilst the foundation } \\
\text { assumed to have } 5 \Omega . \mathrm{m} \text {; due to high conductivity of reinforcing steel }\end{array}$ \\
\hline Tsokas et al. (2011) & $\mathrm{D}, \mathrm{PD}, \mathrm{P}$ & $\begin{array}{c}\text { An ancient Roman wall foundation underneath modern concrete } \\
\text { pavement slabs. The foundation wall contains successive layers of } \\
\text { marble hewn and bricks. }\end{array}$ \\
\hline Abu-Zeid et al. (2006) & $\mathrm{W}, \mathrm{D}$ & $\begin{array}{l}\text { Deteriorated red and grey brick wall, some of the bricks were severely } \\
\text { altered and some voids were generated. }\end{array}$ \\
\hline Chambers et al. (2002) & $\mathrm{W}, \mathrm{D}$ & $\begin{array}{l}\text { Shallow buried foundations were made from concrete, aggregate type } 1 \\
\text { and type } 2 \text {, engineering brick, stone blocks, and loaf and peat mould. }\end{array}$ \\
\hline
\end{tabular}




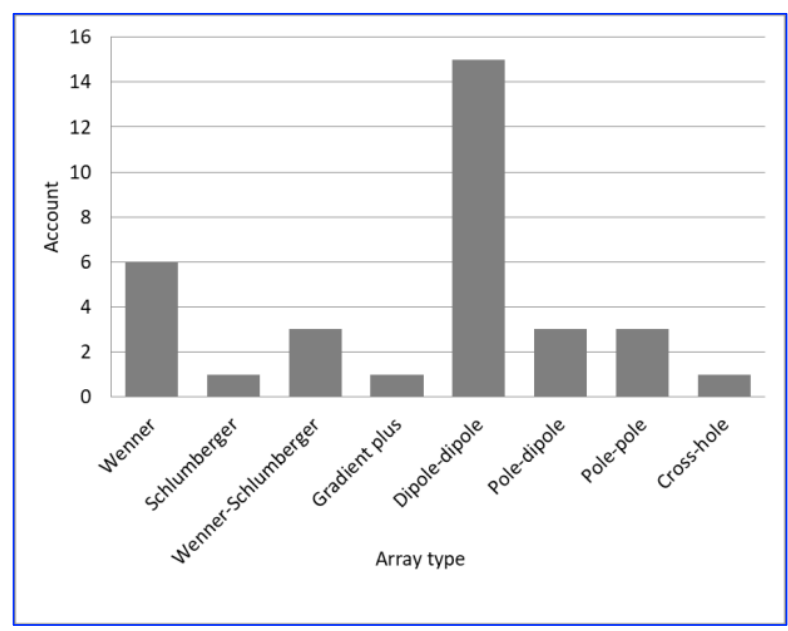

Fig. 2. Frequency of utilizing different electrode configurations used in the previous studies

\subsection{Inversion Algorithms}

Eissa et al. (2019) found the least-square smoothness-constraint algorithm (Fig. 3a) better than the robust inversion algorithm (Fig. 3b) in determining a brick wall that had built inside a gravel fill; by inverting data sets collected using Wenner and dipole-dipole arrays. Where the brick wall is discriminated from the gravel fill on the 2D ERT models inverted using the least-square algorithm. On the other hand, the robust inversion algorithm shows better elimination for the whole target (the gravel fill and the brick wall inside it) from the natural background. That might be related to the nature of the robust algorithm which takes the whole target as one anomaly and without any gradual progression in resistivity values, as applied by other researchers to specify different geological units(Abed et al., 2020).

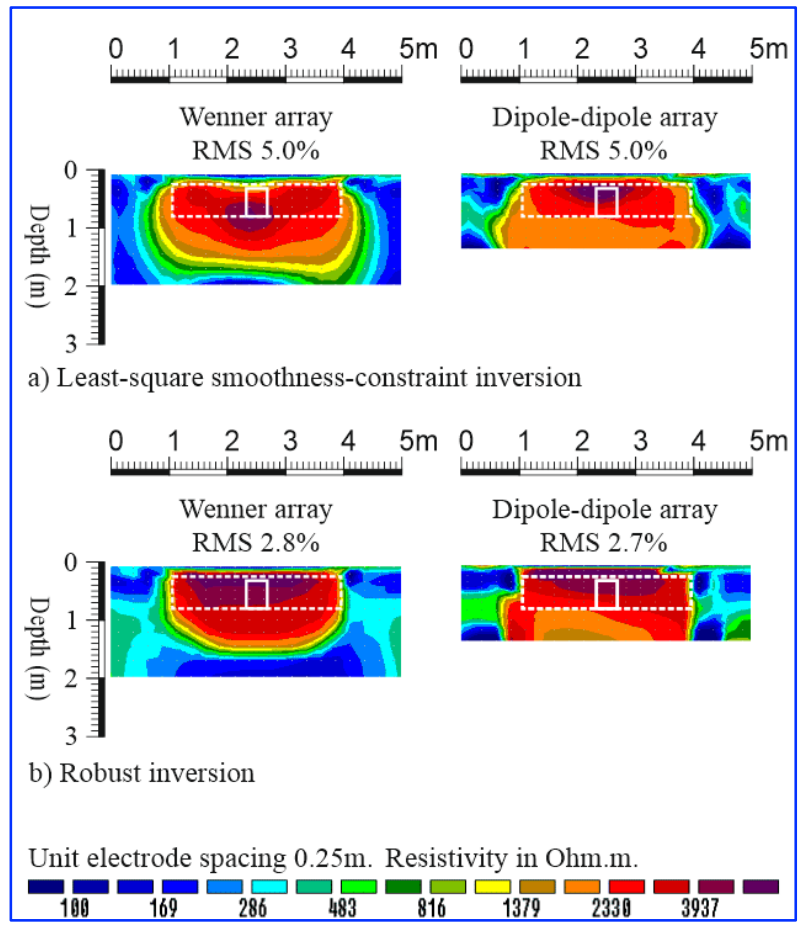

Fig. 3. Least-square smoothness-constraint and robust inversion algorithms effects on $2 \mathrm{D}$ electrical resistivity models obtained from the same target, modified from Eissa et al. (2019). White boxes indicate cleared wall foundation (continuous line) and surrounding test site (dotted line) positions respectively. 


\subsection{The Survey Profile Location on the Ground Surface, it's Orientation and Foundation Dimensions}

The 2D ERT profiles always show the variation in the ground underneath the survey profile on the ground surface. Any anomaly located on the profile side, might be, cannot be imaged, and that depends on the array sensitivity. Different arrays have different sensitivities for vertical and horizontal changes in the ground. The Wenner array is sensitive to about 1.7 of the electrode spacing, the dipole-dipole has 1.8, the pole-dipole has 1.6 and the pole-pole has 0.5 sensitivity on both sides of the survey profile, (Loke, 2004). Chambers et al. ( 2002) found that the array sensitivity to the buried wall was profile orientation dependent. On profiles run parallel to the buried wall, the walls were poorly imaged and hard to be distinguished from the background. On the other hand, the ERT method has been successfully employed to detect buried foundations with an approximate location is known, (Lysdahl et al., 2017).

The array sensitivity might be less important than the electrode spacing if the profile perpendicular to the longest dimension of the buried foundation as Eissa et al. (2019) found; where a $0.36 \mathrm{~m}$ brick wall was imaged using $0.25 \mathrm{~m}$ electrode spacing of Wenner and dipole-dipole arrays using least=square smoothness-constraint algorithm. If the buried foundation location is not even approximately known, multiple 2D profiles at different orientations might be the only available option. Arjwech et al. (2013) performed the electrical resistivity method at five sites and they recommended the following electrode spacings: 1-1.5 m to image a foundation with 1-2 m, $1.5 \mathrm{~m}$ electrode spacing to image a foundation with 2-3 $\mathrm{m}$ in diameter, and if the size of the foundation is more than $3 \mathrm{~m}$, the electrode spacing was suggested to be from $1.5 \mathrm{~m}$ to half of the foundation diameter as a maximum spacing. Arjwech and Everett (2015) utilized a dipole-dipole array with $2 \mathrm{~m}$ electrode spacing to image a buried bridge foundation. The survey was conducted by two profiles passed $0.5 \mathrm{~m}$ from the foundation, the profiles were perpendicular to each other and intersect at one corner of the foundation. The foundation was eliminated from the background with $>80 \Omega . \mathrm{m}$ resistivity reading and it was represented by a rectangular shape on a fence resistivity model (Fig.3).

\subsection{The Foundation Material, Nature of the Background and Moisture Content}

In general, a noticeable contrast between an anomaly and the background resistivities would help to eliminate the anomaly more easily. Abu-Zeid et al. (2006) used Wenner and dipole-dipole arrays to image through a brick wall foundation and to eliminate altered patches. They found the low resistive patches were cracks in the bricks and voids that were filled by salt mud which generated from the brick's degradation. Later on, after mortar injection and hardening, they perform the method again to check out the maintenance quality. It was found the low resistive anomalies have higher resistivity values due to replacing the salt mud material by mortar filling; as they noticed the mud flowed out from holes during mortar injection.

Chambers et al. (2002) applied the resistivity method to investigate buried walls that had been built from different materials; the building materials were concrete, engineering bricks, stone blocks set in mortar, two types of aggregate ( 1 and 2 ), building sand, and moulded leaf and peat mixture. The wall made from leaf and peat was almost indistinguishable from the clayey hosting background. Due to the nature of the wall material, it was expected to have higher moisture content compared with the other walls and decomposition of the organic material might help to increase ions concentration which consequently helps the wall to be more conductive (i.e. less resistive). Although the concrete, stone blocks, bricks, and building sand walls have different building material, they were almost shown by similar resistivity readings. The aggregate wall (type 1 and 3 ) was the most resistive foundation and that was interpreted due to the low moisture content and ultimately high resistivity readings. Arjwech et al. (2013) found different resistivity responses from both the hosting materials and the foundations. In one of the studied sites, named NGES site, the foundation was represented by $<20 \Omega$.m anomaly and this 
low resistivity contrast was interpreted due to the poor conditions of the foundation; where the reinforcing bars were expected to be in contact with the ground. in location 2 a reinforced concrete spread footing was eliminated by $>2000 \Omega$.m resistivity anomaly. In addition, they conducted another resistivity survey on another site, named the westbound bridge over Little Brazos River. At the foundation's location, an anomaly with $2-3 \Omega . \mathrm{m}$ was shown whilst the immediate vicinity ground was eliminated with 5-6 $\Omega . \mathrm{m}$. These close electrical resistivities were interpreted due to the condition of the foundation, it was partly eroded, the reinforcing bars were exposed, corroded and in touch with water (Fig. 4).

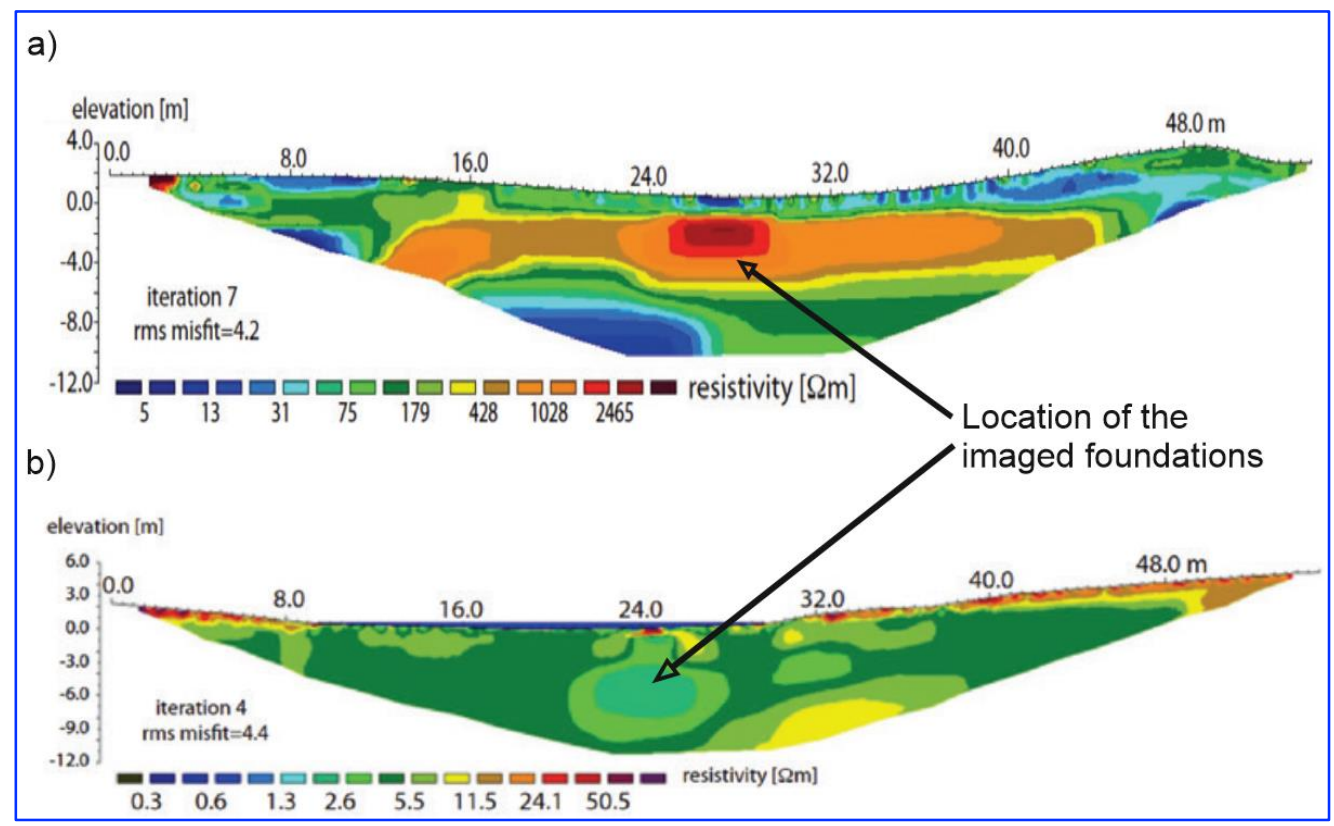

Fig. 4. a) high resistivity anomaly of the NGES spread footing foundation (location 2); b) low resistivity anomaly produced by a drilled shaft bridge foundation at Little Brazos River site, obtained and modified from (Arjwech et al., 2013)

Fernández et al. (2015) succeeded in imaging a historical foundation by utilizing WennerSchlumberger array. Although the study was conducted during the summer season (i.e. dry conditions are expected) the foundation was able to be eliminated from high resistive enclosing material by employing other geophysical data (i.e. GPR surveys and 2D magnetic gradient survey) and historic descriptions of the studied site, in the data interpretation.

In another case study conducted by Arjwech and Everett (2015), the resistivity response of a buried foundation was found to be more than $80 \Omega$.m whilst the resistivity of the immediate vicinity hosting background was less than $10 \Omega . \mathrm{m}$; as represented on the resistivity model. The contrast in the resistivity readings was interpreted due to the nature and to the moisture content of the background which was weathered to moderately weathered shale and clayey and wet deposits.

Moisture content and its salt concentration have influential effects on the resistivity values, the higher moisture and salt concentration the low resistivity readings. Cardarelli et al. (2016) used a combined geophysical and geochemical investigation to determine a buried foundation in Rome, Italy. Electrical resistivity method was performed to locate buried foundations and to investigate the relationship between the foundation and the groundwater. The groundwater at the studied site was able to be characterized as 2-5 m freshwater with resistivity values range 0.1-80 $\Omega . \mathrm{m}, 8-10 \mathrm{~m}$ saltwater presence with resistivity value less than $1 \Omega . \mathrm{m}$, while the foundation depth was estimated to extend up to $8 \mathrm{~m}$ below the floor and its resistivity was estimated 80-100 $\Omega . \mathrm{m}$. In addition, Cardarelli et al. (2018) 
found a buried foundation with resistivity readings higher than $200 \Omega . m$ above the groundwater level, whilst for a deeper foundation (extended depth up to 5-7 m below the floor) with resistivity 30-50 $\Omega . \mathrm{m}$ which was due to the presence of a shallow aquifer (i.e. higher moisture content if not in saturation condition).

Fig. 5 represents the resistivity values of common foundation materials. It shows a wide range of resistivity response from the same material (e.g. bricks foundation from about $20 \Omega$.m to about 3500 $\Omega . m)$. This wide range might be due to several variations, for example, moisture content, salt and ions concentration in the water, variation in the chemistry of the material itself, age and deterioration condition, and so on.

In addition to the wide range of resistivity values, Fig. 5 represents a considerable range of overlapped resistivity values, almost, for all the material. The overlap distributes from about $20 \Omega . \mathrm{m}$ to about $200 \Omega . \mathrm{m}$. The wide range and the overlap properties indicate the ambiguity of the resistivity method for buried foundation studies.

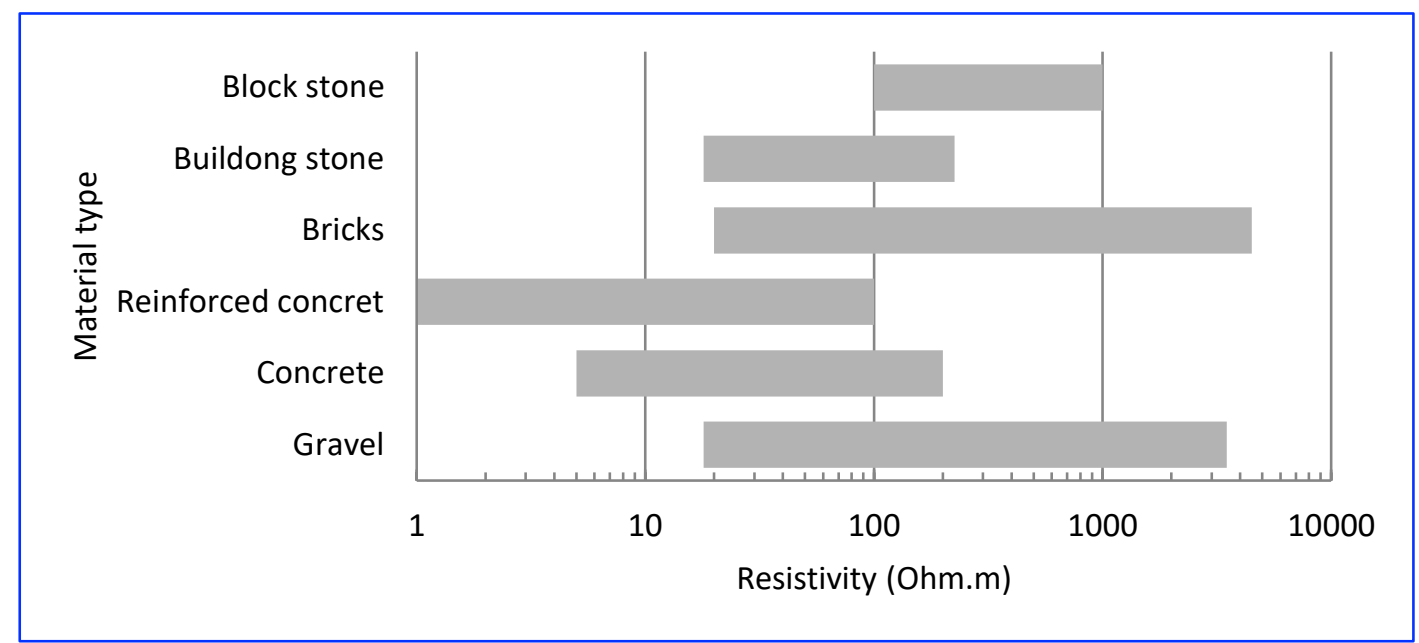

Fig. 5. Electrical resistivity values of common materials which can be used for the foundation construction

\section{Conclusions}

The utilizing of the resistivity method to eliminate buried foundations has been reviewed and insight points have been highlighted. The obtained resistivity models demonstrate the method applicability in that context and the viewed papers highlight a set of effective parameters that influence the method's efficiency. Certain electrode configurations (the Wenner and dipole-dipole) are the most used configurations due to their inherent merits, for example, good signal-to-noise ratio. Electrode spacing is suggested to be at least comparable with the smallest dimension of the targeted foundation. For the profile orientation, surveying in a perpendicular orientation to the foundation can be the most promising survey profile to eliminate the target whilst surveying parallel to the foundation has a lesser chance to detect the foundation and it relies on the electrode spacing, the foundation dimension and the array's sensitivity. Applying different inversion algorithms, especially the least-square smoothness constraint and the robust algorithms might help to reveal the subsurface structure and provide more information about the target. The hosting background conditions (the moisture content, salt and ions concentration) have influential effects on the generated model whilst the state of the buried foundation (deterioration conditions) can change the foundation's response considerably. Conducting comprehensive desk study and utilizing other geophysical surveys (GPR) and traditional tests (excavation) has great potential to generate more suitable models with the reality of the imaged 
subsurface. The certain building material used in the construction of a foundation has a wide range of resistivity values and these values overlap other material's resistivity values. This behaviour makes the interpretation even more ambiguous. The published case studies show that the buried foundation not only represents a higher resistive anomaly compared with the background's resistivity values but also can be revealed with lower resistivity values than the background. Therefore, huge attention should be given due to data processing and interpretation.

\section{Acknowledgements}

The authors are very grateful to the Editor in Chief Prof. Dr. Salih M. Awadh, the Secretary of Journal Mr. Samir R. Hijab. and the Technical Editors for their great efforts and valuable comments.

\section{References}

Abed, A. M., Al-Zubedi, A. S. and Abdulrazzaq, Z. T., 2020. Detected of gypsum soil layer by using $2 \mathrm{~d}$ and $3 \mathrm{~d}$ electrical resistivity imaging techniques in university of anbar, iraq. Iraqi Geological Journal, 53(2): 134144.

Abu-Zeid, N., Botteon, D., Cocco, G., and Santarato, G., 2006. Non-invasive characterisation of ancient foundations in Venice using the electrical resistivity imaging technique. NDT and E International, 39(1), 67-75.

Al-Saadi, O.S., Schmidt, V., Becken, M., and Fritsch, T., 2018. Very-high-resolution electrical resistivity imaging of buried foundations of a Roman villa near Nonnweiler, Germany. Archaeological Prospection, 25(3), 209-218.

Arjwech, R., Everett, M.E., Briaud, J.L., Hurlebaus, S., Medina-Cetina, Z., Tucker, S., and Yousefpour, N., 2013. Electrical resistivity imaging of unknown bridge foundations. Near Surface Geophysics, 11(6): 591-598. doi: 10.3997/1873-0604.2013023.

Arjwech, R., and Everett, M. E., 2015. Application of 2D electrical resistivity tomography to engineering projects: Three case studies. Songklanakarin Journal of Science and Technology, 37(6), 675-681.

Cardarelli, E., De Donno, G., Scatigno, C., Oliveti, I., Martinez, M.P., and Prieto-Taboada, N., 2016. Geophysical and geochemical techniques to assess the origin of rising damp of a Roman building (Ostia Antica archaeological site). Microchemical Journal, 129, 49-57.

Cardarelli, E., De Donno, G., Oliveti, I., and Scatigno, C., 2018. Three-dimensional reconstruction of a masonry building through electrical and seismic tomography validated by biological analyses. Near Surface Geophysics, 16(1), 53-65.

Chambers, J.E., Ogilvy, R.D., Kuras, O., Cripps, J.C., and Meldrum, P.I., 2002. 3D electrical imaging of known targets at a controlled environmental test site. Environmental Geology, 41(6), 690-704.

Chitea, F., Ioane, D., Tolbes, C., Calin, M.C., and Diaconu, A., 2019. Detection of buried foundations in urban environment by electrical resistivity tomography. 10th Congress of Balkan Geophysical Society, BGS, (September).

Eissa, R., Cassidy, N., Pringle, J., and Stimpson, I., 2019. Electrical resistivity tomography array comparisons to detect cleared-wall foundations in brownfield sites. Quarterly Journal of Engineering Geology and Hydrogeology, 53(1), 137-144.

Evangelista, L., de Silva, F., d'Onofrio, A., Di Fiore, V., Silvestri, F., Scotto di Santolo, A., Cavuoto, G., Punzo, M., and Tarallo, D., 2017. Application of ERT and GPR geophysical testing to the subsoil characterization of cultural heritage sites in Napoli (Italy). Measurement: Journal of the International Measurement Confederation. 104: 326-335.

Fernández, G., Teixidó, T., Peña, J.A., Burillo, F., and Claros, J., 2015. Using shallow geophysical methods to characterise the monumental building at the Segeda I site (Spain). Journal of Archaeological Science: Reports. Elsevier Ltd, 2: 427-436.

Giocoli, A., Hailemikael, S., Bellanova, J., Calamita, G., Perrone, A., and Piscitelli, S., 2019. Site and building characterization of the Orvieto Cathedral (Umbria, Central Italy) by electrical resistivity tomography and single-station ambient vibration measurements. Engineering Geology, 260, 105195. 
Gündoğdu, N.Y., Demirci, İ., Demirel, C., and Candansayar, M.E., 2020. Characterization of the bridge pillar foundations using 3d focusing inversion of DC resistivity data. Journal of Applied Geophysics, 172, 1-10.

Keary, P., Brooks, M. and Hill, I. 2002. An Introduction to geophysical exploration, third edition. Blackwell science, Great Britain.

Kermani, B., Coe, J.T., Nyquist, J.E., Sybrandy, L., Berg, P.H., and McInnes, S.E., 2014. Application of Electrical Resistivity Imaging to evaluate the geometry of unknown bridge foundations. 27th Symposium on the Application of Geophysics to Engineering and Environmental Problems, 113-123.

Loke, M. H., 2004. Tutorial: 2D and 3D Electrical Imaging Surveys. 136.

Lysdahl, A.K., Bazin, S., Christensen, C., Ahrens, S., Günther, T., and Pfaffhuber, A.A., 2017. Comparison between 2D and 3D ERT inversion for engineering site investigations - A case study from Oslo Harbour. Near Surface Geophysics, 15(2): 201-209.

Reynolds, J. M., 2011. An Introduction to Applied and Environmental Geophysics, second edition. John Wiley \& Sons.

Su, M., Liu, Y., Xue, Y., Qu, C., Wang, P., and Zhao, Y., 2020. Detection Method of Pile Foundation on Subway Lines Based on Cross-Hole Resistivity Computed Tomography. 34(1992): 1-9.

Tsokas, G.N., Tsourlos, P.I., Vargemezis, G.N., and Pazaras, N.T., 2011. Using surface and cross-hole resistivity tomography in an urban environment: An example of imaging the foundations of the ancient wall in Thessaloniki, North Greece. Physics and Chemistry of the Earth. 36(16), 1310-1317.

Tucker, S.E., Briaud, J.L., Hurlebaus, S., Everett, M.E., and Arjwech, R., 2015. Electrical resistivity and induced polarization imaging for unknown bridge foundations. Journal of Geotechnical and Geoenvironmental Engineering, 141(5).

Vargemezis, G., Diamanti, N., Fikos, I., Stampolidis, A., Makedon, T., and Chatzigogos, N., 2016. Ground penetrating radar and electrical resistivity tomography for locating buried building foundations: A case study in the city centre of Thessaloniki, Greece. Bulletin of the Geological Society of Greece, 47(3), 1355.

Wang, H., and Hu, C.-H., 2015. Identification on Unknown Bridge Foundations Using Geophysical Inspecting Methods. The e-Journal of Nondestructive Testing, 20(11), 905-912.

Wang, H., Hu, C., and Wang, C., 2013. Electrical resistivity tomography to inspect bridge foundations. Third International Conference on Geotechnique, Construction Materials and Environment, Nagoya, Japan, 1315, 2-7.

Wu, P.-L., and Lin, C.-P., 2013. Determining Unknown Bridge Foundation Depth Using 2-Dimensional Electrical Resistivity Tomography, 197-201. 